This item was submitted to Loughborough's Research Repository by the author.

Items in Figshare are protected by copyright, with all rights reserved, unless otherwise indicated.

\title{
In-cycle and life-time friction transience in piston ring-liner conjunction under mixed regime of lubrication
}

PLEASE CITE THE PUBLISHED VERSION

http://dx.doi.org/10.1177/1468087413519783

PUBLISHER

(c) Sage

VERSION

AM (Accepted Manuscript)

LICENCE

CC BY-NC-ND 4.0

\section{REPOSITORY RECORD}

Styles, Gema, Ramin Rahmani, Homer Rahnejat, and Brian Fitzsimons. 2014. "In-cycle and Life-time Friction Transience in Piston Ring-liner Conjunction Under Mixed Regime of Lubrication". Loughborough University. https://hdl.handle.net/2134/14120. 
This item was submitted to Loughborough's Institutional Repository (https://dspace.lboro.ac.uk/) by the author and is made available under the following Creative Commons Licence conditions.

\section{creative
commons}

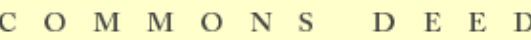

Attribution-NonCommercial-NoDerivs 2.5

You are free:

- to copy, distribute, display, and perform the work

Under the following conditions:

Attribution. You must attribute the work in the manner specified b the author or licensor.

Noncommercial. You may not use this work for commercial purposes.

No Derivative Works. You may not alter, transform, or build upon this work.

- For any reuse or distribution, you must make clear to others the license terms of this work.

- Any of these conditions can be waived if you get permission from the copyright holder.

Your fair use and other rights are in no way affected by the above.

This is a human-readable summary of the Leqal Code (the full license).

\section{Disclaimer 만}

For the full text of this licence, please go to: http://creativecommons.org/licenses/by-nc-nd/2.5/ 
DOI: $10.1177 / 1468087413519783$

(Accepted Version)

\title{
In-cycle and life-time friction transience in piston ring-liner conjunction under mixed regime of lubrication
}

\author{
G. Styles ${ }^{1}$, R. Rahmani ${ }^{1}$, H. Rahnejat ${ }^{1 *}$ and B. Fitzsimons ${ }^{2}$ \\ ${ }^{1}$ Wolfson School of Mechanical and Manufacturing Engineering, Loughborough University, \\ Loughborough, Leicestershire LE11 3TU, UK \\ ${ }^{2}$ Aston Martin Lagonda, Gaydon, Warwickshire, UK
}

\begin{abstract}
The piston ring/cylinder liner conjunction can experience various regimes of lubrication during piston strokes inside the engine cylinder. In the current engines, the nature of lubrication usually remains hydrodynamic at mid-stroke whilst a mixed regime of lubrication may be experienced at and near reversals. The direct contact between the tips of some of the asperities of opposing surfaces leads to mixed (partial) regime of lubrication. A model proposed by Greenwood and Tripp can be used to predict asperity level contribution to the total piston friction. At the same time Reynolds equation can be employed to predict the portion of load carried by the lubricant trapped between the asperities. Friction between the asperity tips is usually proportional to the load that they support; stated in terms of a proportionality factor; i.e. coefficient of friction. The surfaces are usually furnished with hard wear resistant coatings and in parts by solid lubricants. Both the piston rings and cylinder liner surfaces are usually coated. These coatings change the friction characteristics of the counterfaces because of their surface topography as well as material mechanical properties. AFM is used to obtain surface topographical parameters in contact tapping mode. The corresponding surface topographical parameters are obtained from representative regional areas of the contacting solid surfaces, using a Talysurf. The combination of topography and coating characteristics are used to develop the necessary parameters for a boundary friction model. A numerical model of the top compression ring to cylinder liner is developed based on mixed-hydrodynamic regime of lubrication. The results for friction and the effect of coating on the power loss and wear of the conjunction are discussed in the paper.
\end{abstract}

Keywords: Boundary friction; Asperity interaction; Piston-ring/cylinder liner contact; Advanced coating; Oil consumption

*Corresponding author: H. Rahnejat: H.Rahnejat@lboro.ac.uk 


\section{INTRODUCTION}

There is an ever increasing demand on energy resources with their consequent rising costs. The piston compression ring-cylinder liner conjunction accounts for approximately $2 \%$ of the energy losses in an internal combustion engine (Fitzsimons [1]). There is also an imminent need for reduction in the emission levels. Therefore, a plethora of palliative measures have emerged in order to reduce the parasitic frictional losses and guard against their untoward effects such as poor fuel efficiency, increased harmful emissions and wear of surfaces. The inordinate cost of physical prototype testing and the multitude of perceived alternative methods of palliation have resulted in an increased use of predictive tools. Since the initial analytical approach by Furuhama [2], there have been increasing levels of detail in predictive methods, including further salient practical features in the analysis tools. Initially, the improvements in analyses were as the result of a better understanding of regimes of lubrication and improvements in numerical procedures (Dowson et al [3], Ma et al [4], Akalin and Newaz [5], Bolander et al [6], Mishra et al [7, 8], D’Agostino and Senatore [9] and Rahmani et al [10]). Good agreement is shown between the predicted and the measured friction presented by Furuhama and Sasaki [11] by a number of contributions such as those of Akalin and Newaz [12] and Mishra et al [8]. However, differences still exist, particularly at dead centre reversals. In such locations mixed or boundary regimes of lubrication are prevalent. These are contributions to friction from a thin film of lubricant (viscous shear) as well as interactions of ubiquitous asperities on the contiguous counterface surfaces (boundary friction). The latter is a complex mechanism, especially because knowledge of boundary shear strength of often coated surfaces as well as the presence of a thin adsorbed film of lubricant species is only slowly emerging (Al-Samieh and Rahnejat [13] and Chong et al, [14]). Consequently, boundary friction models used are still largely based on the earlier work of Greenwood and Tripp [15], which assumes a Gaussian distribution of asperities on the counterfaces, an assumption which cannot be always upheld as a true representation of real surfaces. Furthermore, any thin adsorbed surface film is assumed to undergo shear according to the bulk lubricant's Eyring shear stress. Nevertheless, the use of this method has resulted in better prediction of in situ conditions, if accurate measurements of surface topography and shear strength characteristics of coatings can be made. Therefore, in the more detailed and advanced recent analyses friction is viewed as a lubricant-surface system response (Erdemir [16], Chong et al [17]).

The in-cycle transient nature of the piston-cylinder liner conjunction encompasses the breadth of regimes of lubrication, requiring a transient analysis [18]. In all the engine strokes, as well as at piston mid-span position in the power stroke fluid film regime of lubrication is expected. Thus, any reduction of friction is largely incumbent upon the use of a low viscosity lubricant. There is, however, a limit in reducing the lubricant viscosity as its load carrying capacity would be compromised, particular in the higher load intensity contacts such as the cam-follower pair [19]. The same lubricant is used to supply all the internal combustion engine conjunctions as of practical necessity. A significant portion (nearly 30\%) of frictional power loss in ring-liner conjunction occurs at the top dead centre reversal in the transition from the compression stroke to the power stroke (Rahmani et al [11]). This provides an opportunity for the use of hard wear resistant coatings which also enjoy a smoother surface topography, thus palliate some of the untoward effects of friction. However, engine testing work has shown that contrary to expectations hard coatings such as Ni-SiC, DLC or Ni-CrMo do not always produce this perceived desired effect, mainly because of the increased chance of adhesion, as well as the often oleophobic nature of some hard coatings [20,21]. 
No study of note has combined the effect of coatings on the tribological performance of ringliner contact under boundary interactions with a rough surface contact model. The first step in such a process is to obtain realistic boundary parameters; topography and shear characteristics. This paper reports on such an approach and investigates their influence on friction through their inclusion in numerical prediction of ring-liner contact.

\section{EXPERIMENTAL METHODOLOGY AND MEASUREMENTS}

\subsection{Compression ring face-width geometry and composition}

Surface topography and shear characteristics of coated compression rings were studied in order to evaluate their boundary friction behaviour at dead centre piston reversals. Wear of ring coatings yields transient boundary friction throughout the useful life of the ring which is also affected by changes in the ring face-width geometry [11, 22]. Therefore, the surface characteristics and overall geometry of new and worn top compression rings are studied (Figure 1). The two worn rings investigated correspond to 10,000 km and 150,000 km use respectively. They are so chosen in order to investigate the variation in boundary characteristics from that of a new ring at various stages of wear. The ring with $10,000 \mathrm{~km}$ service represents one which has just undergone its initial running-in wear, whilst that with significantly higher use is classified as fully embedded and at the end of its useful life.

The investigated compression ring type is used in a high performance V12 Aston Martin engine. It is made of an alloy steel (C $0.56 \%$, Ni $0.20 \%$, Cr $0.60 \%)$ with typical hardness of 44-53 HRC, tensile strength of $1.65 \mathrm{GPa}$ and fatigue strength of $955 \mathrm{MPa}$. The ring facewidth is $1.2 \mathrm{~mm}$, comprising 3 sections. The load bearing central section of the ring is an insert of width $0.6 \mathrm{~mm}$, plasma sprayed with a mixture of molybdenum and $\mathrm{Ni}$-Cr hardening alloy with a nominal thickness of $100 \mu \mathrm{m}$. The inclusion of Molybdenum reduces the solid solubility of the coated surface against the cast iron cylinder liner insert because of its low weldability. The top and bottom edges of the ring axial face-width are relieved with small chamfers and coated with a running-in sacrificial phosphate-manganese coating, which acts as a solid lubricant. 


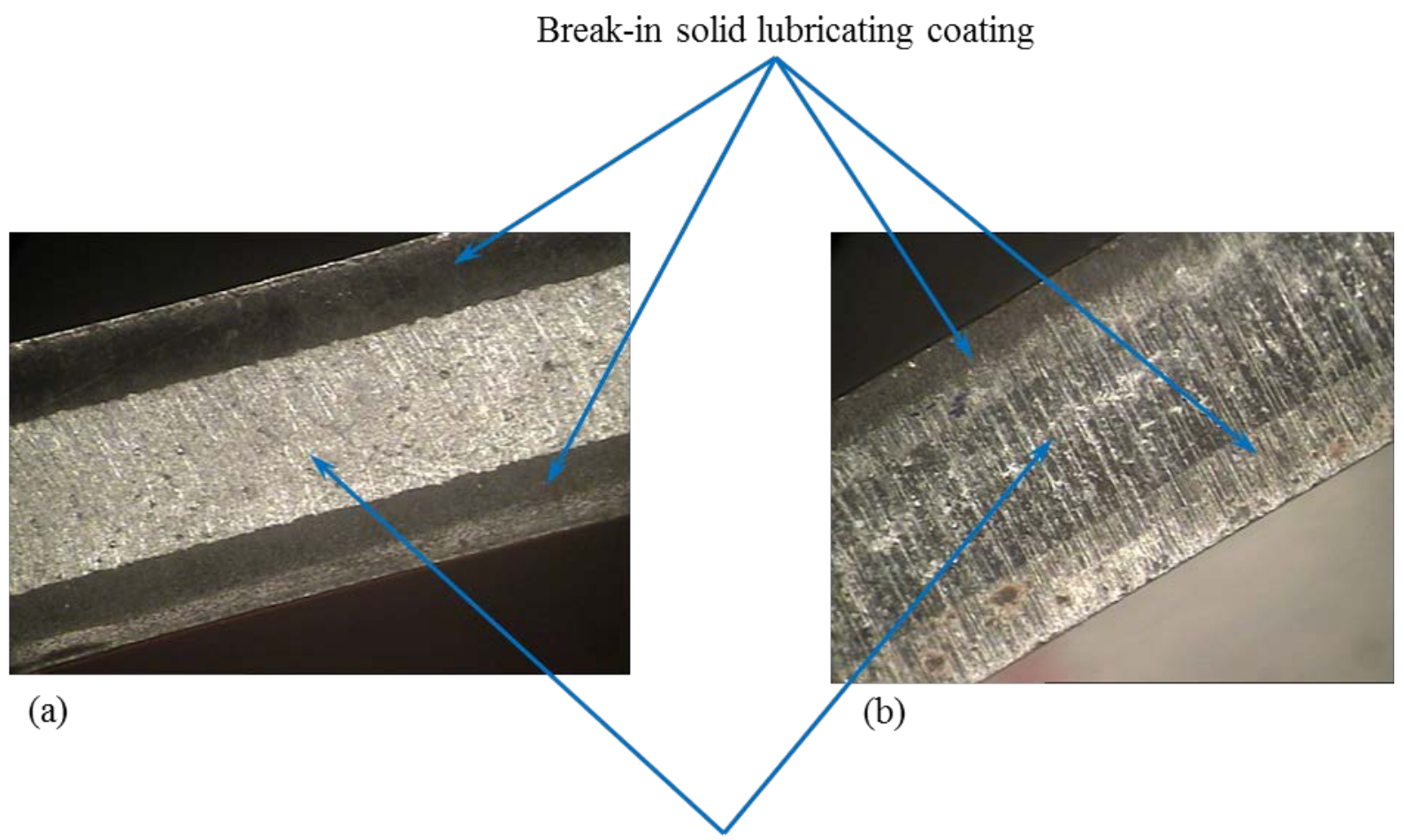

Plasma sprayed insert

Figure 1: Images of the compression ring surface; (a)- New ring, (b)- Worn embedded ring

The plasma sprayed coating is anisotropic with significant porosity, where the cavities are expected to act as micro-reservoirs of lubricant, thus reducing the effect of boundary interactions. Even in its nominally embedded worn state (shown in Figure 1(b), corresponding to the ring with $150,000 \mathrm{~km}$ use), where prominent surface features have significantly worn, the porosity level remains at approximately $15 \%$ of the total surface area (Figure 2). This shows that the hard wear resistant coating is sufficiently effective in protecting the base alloy steel substrate. The ring's nominally fully-embedded state is obtained through severe accelerated wear in engine testing procedure shown in Figure 3. This is a test procedure including typical cycles shown in the figure with intermittent idle condition at $1000 \mathrm{rpm}$, followed by maximum torque at wide open throttle (WOT) at 5500 rpm and at maximum power tests with WOT at $6750 \mathrm{rpm}$. The fully embedded worn ring is the one subjected to such a test cycle for 150 hour high speed durability test, consisting of 225 cycles of 40 min of control power. The run-in partially worn ring has been subjected to the same cyclic test procedure for 10 hours. 


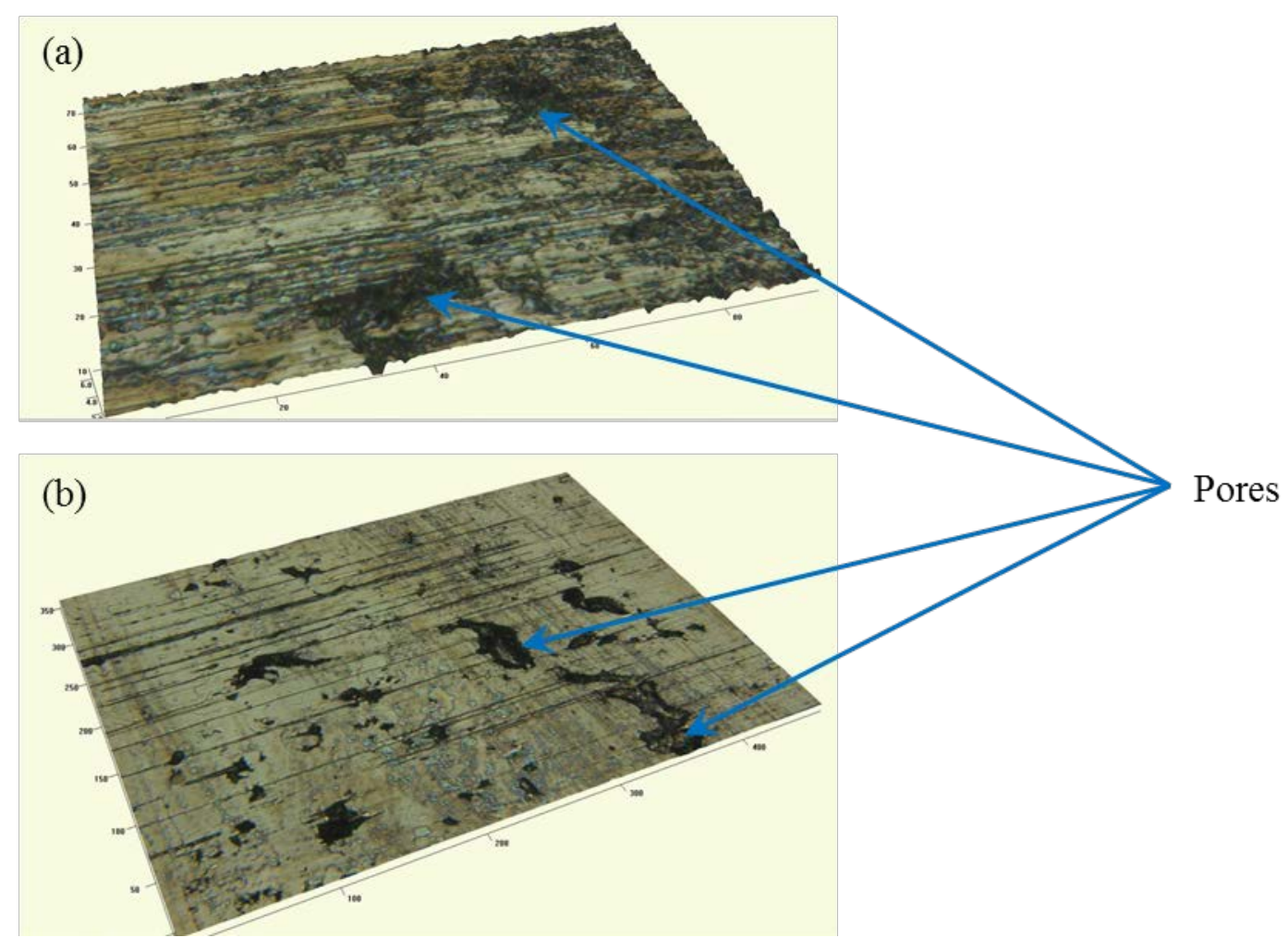

Figure 2: Porous composition of Ni-Cr-Mo plasma sprayed coating; (a)- New ring, (b)- Worn embedded ring

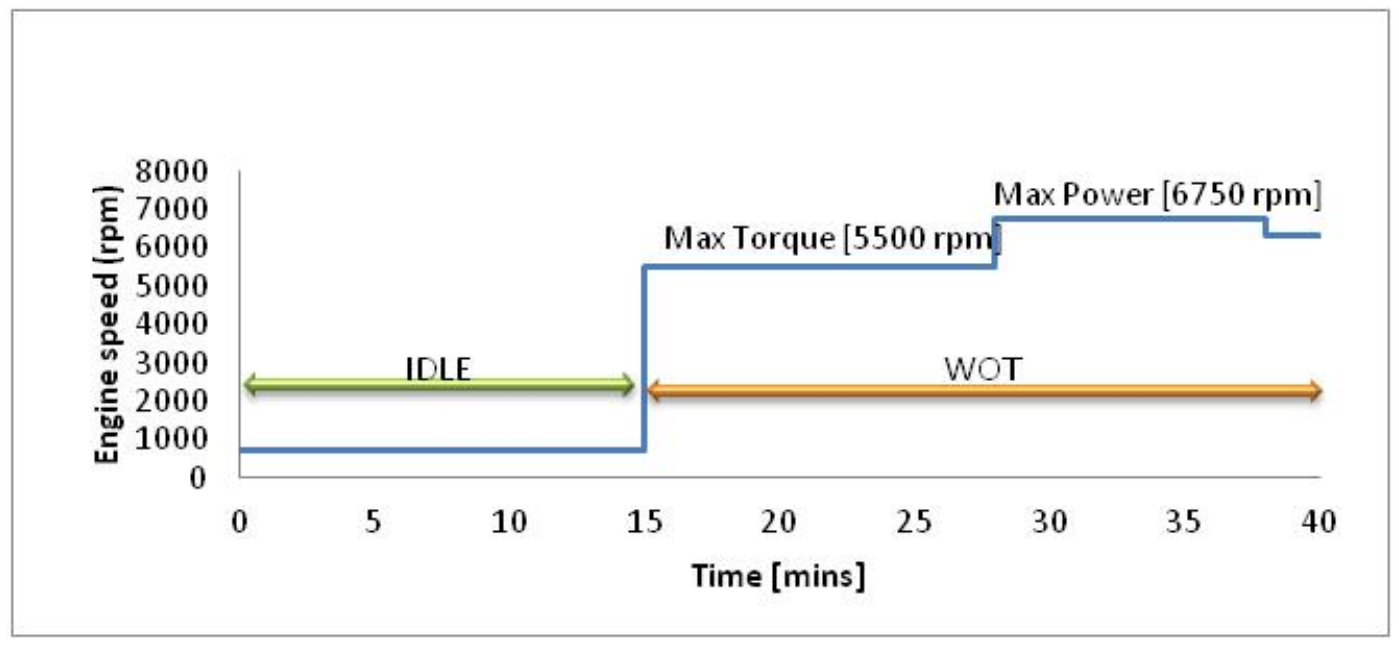

Figure 3: Severe durability engine testing procedure

Referring back to Figure 1(b) one can observe that the sacrificial coating on ring face-width edges is almost completely worn away. The wear is more severe at the lower edge of the ring because of higher pressures in the power stroke causing the ring to twist and run on its lower edge. This asymmetrical wear of the ring face-width can be observed in Figure 4, which shows the ring face-width profile for the new and the worn rings are measured by an optical Talysurf profilometre. 


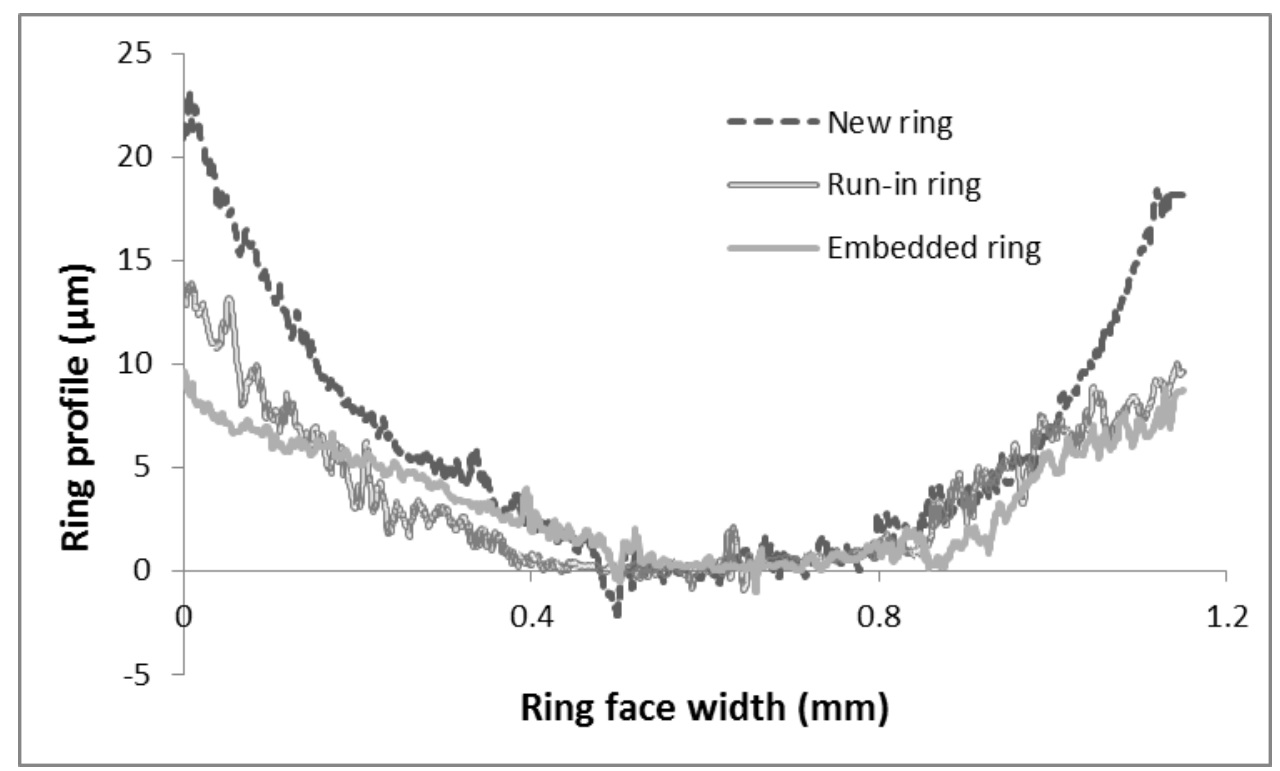

Figure 4: Ring face-width profile for the new and worn rings

Note that unlike the symmetrical profile generally assumed in numerical predictive work for the ring face-width profile in the form of a parabola, the geometry of the ring is actually asymmetrical and best described by a hexanomial curve $\left(6^{\text {th }}\right.$ order polynomial) as described by Rahmani et al [11]. The worn rings can also be fitted by a hexanomial curve. Therefore, a realistic analysis would yield significantly different lubricant entrainment into the contact than that generally assumed. Furthermore, the inlet wedge effect varies with the state of wear of the ring edge profiles. The effect of inlet wedge height is discussed in detail in Morris et al [22]. Briefly, a larger inlet wedge causes a higher pressure gradient and can lead to greater pressure-induced shear. The state of wear of ring changes the inlet wedge as shown in Figure 4 and is taken into account in the analysis described later.

Whilst the inlet wedge geometry affects the hydrodynamic contact conditions and thus the contribution due to viscous friction, surface topography and shear characteristics of coated surfaces affect the boundary friction contribution.

\subsection{Surface topography and roughness parameters}

When a coherent film of lubricant of sufficient thickness does not separate the contiguous surfaces, some degree of interaction of asperity tips on the contiguous surfaces takes place. It is generally assumed that an ultra-thin film of lubricant is adsorbed at the asperities' summits and shears in a non-Newtonian manner at the Eyring shear stress of the lubricant used $[15,23]$. In addition to the Eyring shear stress, the boundary friction model (Section 3) takes into account the topographical surface parameters including the average surface roughness, $\sigma$, the average asperity summit radius, $\beta$ and the asperity density per unit area, $N$. Mechanical material properties of the counterface surfaces, including the coatings, such as the Young's modulus of elasticity, $E$ and the coefficient of the boundary shear strength, $\varsigma$ are also taken into account. Thus, these parameters need to be accurately measured.

A Form Talysurf (PGI-1250) was used to measure the liner surface topography based on the ISO 13565.2 standard. The measurements taken near the TDC at thrust-side were used for the current analysis. For the engine investigated here a mixed regime of lubrication is noted at 
the TDC, whilst at other piston locations a hydrodynamic regime of lubrication is prevalent (Rahmani et al [11]). The liner surface roughness is found to be $\sigma=0.26 \mu \mathrm{m} \mathrm{Ra}$.

Unlike the liner surface, the coated surface of ring's load bearing land, as already noted, is anisotropic with significant porosity. Thus, its surface roughness varies greatly from region to region. This makes any representative topographical measurement quite difficult. A white light interferometer (Zygo) with a measurement resolution of $1 \mathrm{~nm}$ was used to obtain topographical images of areas of the surface containing the most prominent features. These are the areas of the surface with a greater chance of asperity interaction with the counterface liner surface. A typical hierarchical process for the measurements is depicted in Figure 5 for a new ring. Many regional measurements were carried out and an average value for surface roughness was obtained in this manner for both the new ring and the worn ones. These were $R a=0.41 \mu \mathrm{m}, R a=0.43 \mu \mathrm{m}$ and $R a=0.24 \mu \mathrm{m}$ for the new, run-in and embedded worn rings respectively. Based on the traditional Amontons-Coulomb friction laws, the results obtained would suggest a lower boundary friction for the worn rings. However, these laws are idealized and disregard a number of salient practical issues, such as changes in the surface material property and typical asperity geometry through the wear process.

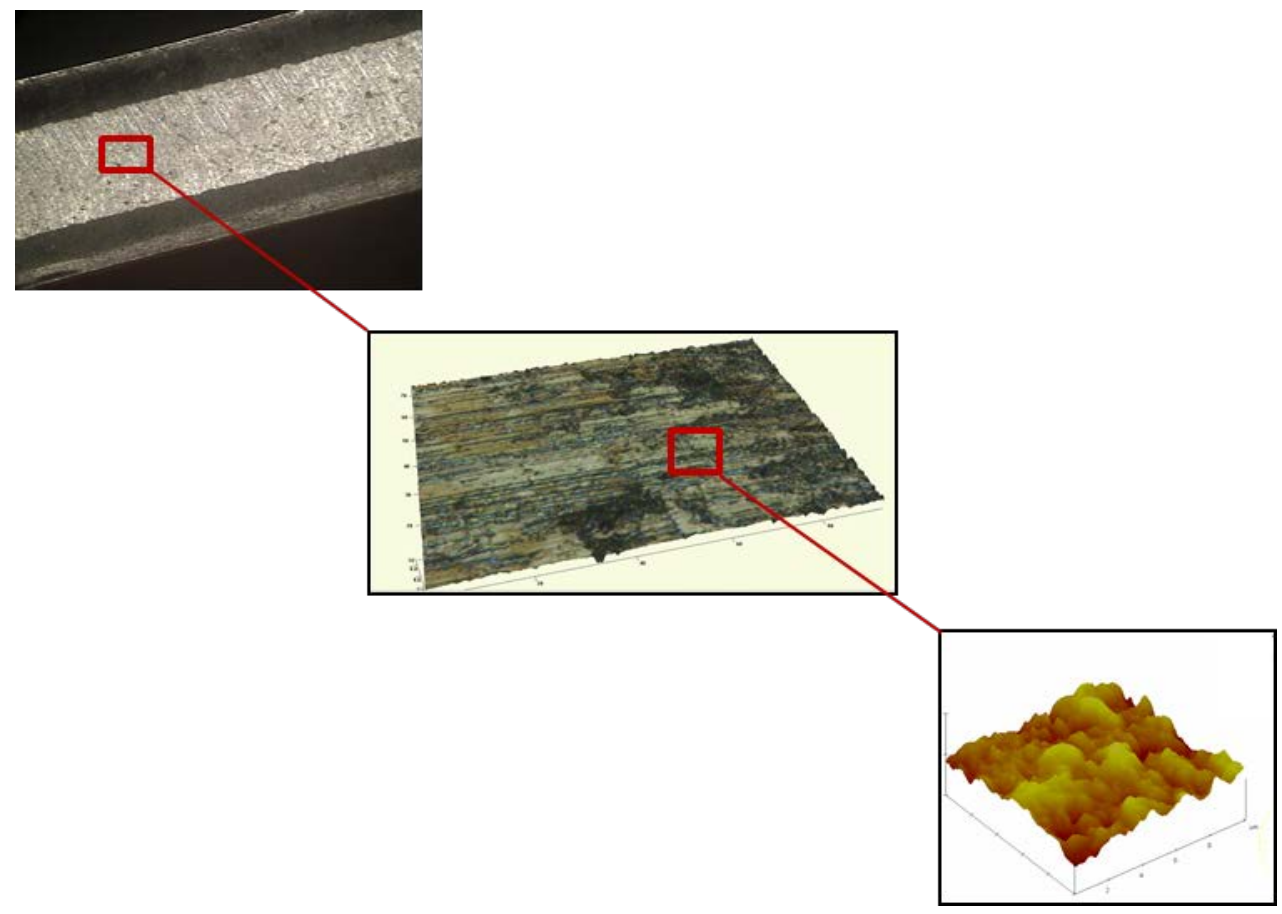

Figure 5: Hierarchical surface measurement process with white light interferometry

Figures 1(b) and 2(b) showed that as the phosphate-manganese coating on the edges of the ring face-width wears, a thin layer of transfer film forms on the central ring's Ni-Cr-Mo hard coating. Furthermore, heat degradation of the coating occurs throughout its service life. Therefore, the boundary shear strength of the surface changes. This is a parameter (analogous to asperity coefficient of friction) used in equation (8) in section 3. The change in the asperity geometry, as represented by the Tabor's roughness parameter $N \beta \sigma$ [24] and asperity slope $\sigma / \beta$ alters the asperity contact area and load share, hence the friction. Therefore, the combination of changing surface topography and the surface shear strength affect the 
boundary friction in real situations. Hence, the surface topographical parameters $N, \beta$ as well as the coefficient of the boundary shear strength, $s$, must be measured and calculated accurately, the last one using an atomic force microscope (AFM) in contact mode (Prokopovich et al [25]).

To obtain the composite surface roughness parameters, a method described by Arcoumanis et al [26]) is used. Using the data obtained from white light interferometry, the required data for the Tabor's roughness parameter (i.e. the asperity peak density, $N$ and average radius of curvature of the asperity peaks, $\beta$ ) are obtained as:

$N=\frac{1}{6 \pi \sqrt{3}}\left(\frac{m_{4}^{c}}{m_{2}^{c}}\right)$

and

$\beta=\frac{3 \sqrt{\pi}}{8} \sqrt{\frac{1}{m_{4}^{c}}}$

where, $m_{4}^{c}=m_{4}^{1}+m_{4}^{2}$ and $m_{2}^{c}=m_{2}^{1}+m_{2}^{2}$ are the composite $4^{\text {th }}$ and $2^{\text {nd }}$ spectral moments of surfaces 1 and 2 (ring and the liner) (Arcoumanis et al [26]). These spectral moments are defined as:

$m_{2}=\overline{\left(\frac{d z(x)}{d x}\right)^{2}}$

$m_{4}=\overline{\left(\frac{d^{2} z(x)}{d x^{2}}\right)^{2}}$

The results obtained from the measurement and subsequent calculations for the surface topographical parameters are listed in Table 1.

Table 1: Roughness parameters

\begin{tabular}{|c|l|c|c|c|}
\hline Parameter & Unit & New ring/liner & Run-in ring/liner & Embedded ring/liner \\
\hline$N$ & $\mu^{-2}$ & 0.097 & 0.100 & 0.101 \\
\hline$\beta$ & $\mu \mathrm{m}$ & 1.56 & 1.34 & 1.82 \\
\hline$\sigma$ & $\mu \mathrm{m}$ & 0.48 & 0.50 & 0.35 \\
\hline
\end{tabular}

\subsection{Determining the coefficient of boundary shear strength}

Mate [27] was the first to observe the atomic scale friction force acting on a tungsten wire tip, sliding on the basal plane of a graphite surface, using a FFM (Friction Force Microscope). Thereafter, there have been many attempts in measuring the coefficient of friction using a FFM [28-32]. The main issue in measuring friction force with an FFM is the rather complex required calibration procedure. Various methods have been reported for the calibration of the measured forces in the literature. The first of such methods was described by Ruan and Bhushan [33]. They described two methods to measure friction: the 'Height' mode with parallel scans and 'Aux' mode with perpendicular scans. Warmack et al [34] described a calibration procedure for triangular cantilever tips. Ogletree et al [35] presented an in situ 
experimental procedure to determine the response of a cantilever to applied lateral forces in terms of its normal force response. This procedure is called the 'wedge' calibration method. The reason for developing such a procedure was that with the methods existing at the time it was difficult to obtain reproducible quantitative measurements. This is because parameters such as the normal and lateral cantilever force constants, the tip height, the deflection sensor response, and the tip structure and composition at the tip-surface contact are either unknown or difficult to precisely measure [35]. For similar reasons Buenviaje et al [36] proposed the 'blind calibration method' of an AFM calibration method which uses the measured lateral force on the AFM cantilever. The current study uses a method similar to that of Buenviaje et al [36].

The compression rings in various states of wear were studied using a Veeco 3.5 nanoscope in LFM (Lateral Force Mode) to obtain frictional behaviour. The cantilever tips used were Vshaped Si3N4 with a nominal spring constants of $0.12 \mathrm{~N} / \mathrm{m}$. A silicon wafer was used to calibrate the applied loads and frictional forces. The details of the calibration are given in Appendix A. The procedure in Appendix A is followed for a number of prepared samples from various compression rings in the different states of wear noted above. The results are shown in Figure 6. The slope of the fitted lines for each case determines the coefficient of friction for the given surfaces and tabulated in Table 2.

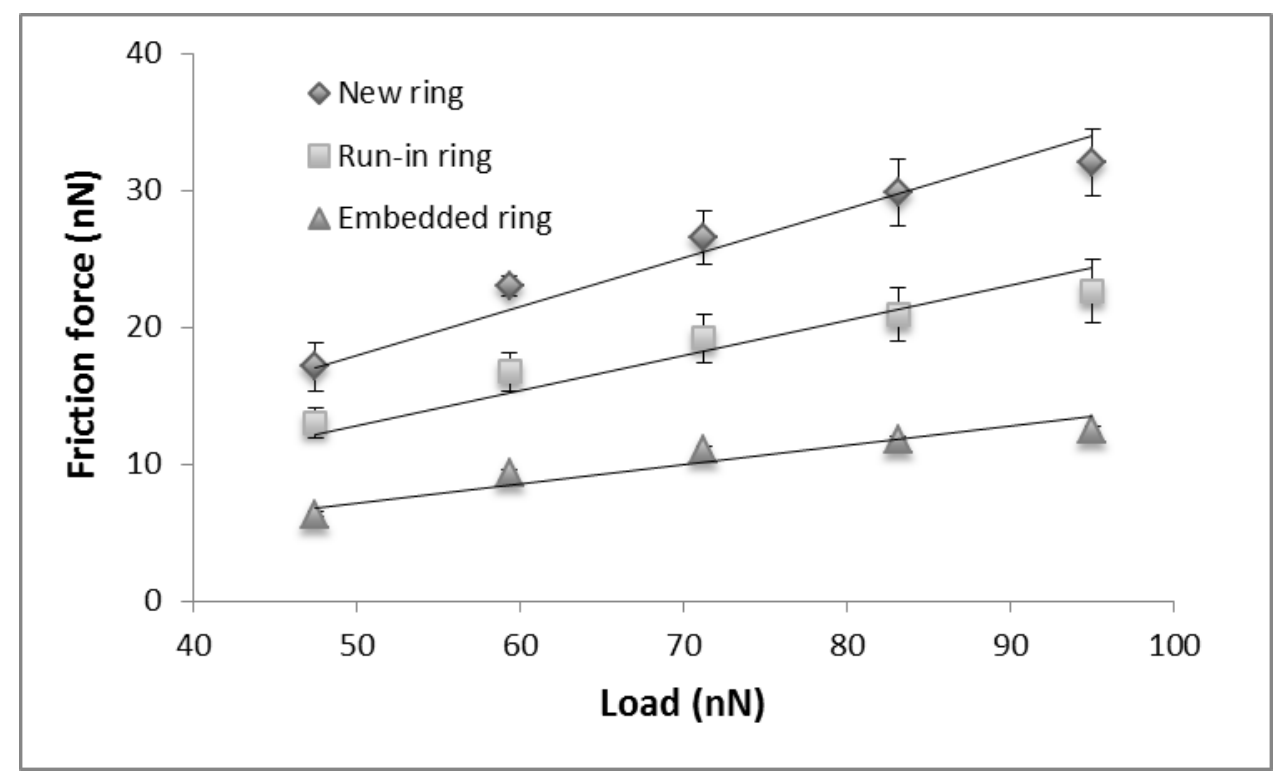

Figure 6: Variation of friction for various applied loads

Table 2: Coefficient of boundary shear strength for each ring sample

\begin{tabular}{|c|c|}
\hline Ring type & Coefficient of boundary shear strength, $\boldsymbol{\varsigma}$ \\
\hline New & 0.3581 \\
\hline Run-in & 0.2565 \\
\hline Bedded & 0.1423 \\
\hline
\end{tabular}




\section{NUMERICAL ANALYSIS}

\subsection{Mathematical Formulation}

Assuming instantaneous quasi-static equilibrium at any crank angle position, $\varphi$, the contact load is determined by the outward ring tension force towards the cylinder liner and the gas pressure force also acting radially outwards behind the inner rim of the ring $[7,8,11]$. This contact force is equilibrated by the hydrodynamic reaction due to the viscous action of a lubricant film and any asperity contact load share (as the result of any direct contact of the contacting surfaces) [37], thus:

$W=\left(p_{e}+p_{g}\right) A=W_{h}+W_{a}$

where, the elastic pressure: $p_{\mathrm{e}}=\frac{F_{t}}{b B}$ and it is assumed that $100 \%$ of the instantaneous gas pressure $p_{g}$ acts behind the compression ring. $A$ is the apparent contact area of the ring-bore conjunction. For simplicity the bore is assumed to be an idealised right circular cylinder. In practice, the bore is out-of-round [11]. Thus, for the assumed circumferentially conforming ring: $A=\pi B b$. A small proportion of the contact area is due to direct asperity contacts as a function of surface roughness and the instantaneous prevailing film thickness, being the Stribeck's oil film parameter, $\lambda=h / \sigma$ :

$A_{a}=\pi^{2}\left(N \beta \sigma_{s}\right)^{2} A F_{2}(\lambda)$

Where:

$F_{2}(\lambda)=\max \left\{-0.002 \lambda^{5}+0.028 \lambda^{4}-0.173 \lambda^{3}+0.526 \lambda^{2}-0.804 \lambda+0.500,0\right\}$

The asperity load share is [15]:

$W_{a}=\frac{8 \sqrt{2}}{15} \pi\left(N \beta \sigma_{s}\right)^{2} \sqrt{\frac{\sigma}{\kappa}} E^{\prime} A F_{5 / 2}(\lambda)$

where, $\frac{2}{E^{\prime}}=\frac{1-v_{1}^{2}}{E_{1}}+\frac{1-v_{2}^{2}}{E_{2}}$, and the statistical functions are [38]:

$F_{5 / 2}(\lambda)=\max \left\{-0.004 \lambda^{5}+0.057 \lambda^{4}-0.296 \lambda^{3}+0.784 \lambda^{2}-1.078 \lambda+0.617,0\right\}$

Boundary friction may be stated as [38]:

$f_{b}=\tau_{0} A_{a}+\varsigma W_{a}$

The underlying hypothesis in the use of equation (8) is that the asperities are wetted by adsorption of an ultra-thin film of boundary active molecules within the lubricant. Briscoe and Evans [39] assume that a thin adsorbed film of boundary active lubricant species are subject to non-Newtonian shear. This non-Newtonian shear behaviour commences at the Eyring shear stress of the lubricant, $\tau_{0}$. An alternative hypothesis would be that the opposing asperities form adhesive junctures which are submerged in the menisci formed between them. Therefore, boundary friction may be considered as the effort required to break such meniscus 
bridges (Bowden and Tabor [40]) in addition to overcoming the adhesion of cold welded asperity junctures themselves [41]. Such an approach is reported by Teodorescu and Rahnejat [42]. A shortcoming of the approach reported in [40] is the need to specify the proportion of contact in dry contact of asperities. On the other hand the approach in [38] makes use of asperity contact area $A_{a}$, based on the assumption of asperity distribution, which is considered to follow a Gaussian distribution as in [15]. Additionally, in the current analysis, an ultra-thin adsorbed film is assumed at the tip of relatively stiff asperities, not subjected to adhesive junctures due to low surface energy, and which are of insufficient thickness to form meniscus bridges.

The coefficient of boundary shear strength at asperity level, $\varsigma$ reduces in the presence of a thin adsorbed film of boundary active molecules at the summit of asperities. Chong et al [43] have used statistical mechanics to predict shear behaviour of such adsorbed films and Ruan and Bhushan [33] have carried out measurement of the same for different lubricants. They both show very small changes in the value of the asperity coefficient of shear strength, because of small area of asperity contact. Nevertheless, it is important to note that the value of $\varsigma$ used here corresponds to dry contact measurements with AFM. This means that the results presented later can be representative of a base lubricant with no boundary active additives.

Appropriate values for $\varsigma$ are measured and listed in Table 2. Eyring shear stress and all other rheological properties of the lubricant are listed in Table 3.

At any given crank angle, the hydrodynamic share of contact load is obtained as:

$W_{h}=\iint p_{h} d x d y$

where, the hydrodynamic pressure distribution is obtained through solution of Reynolds equation:

$\frac{\partial}{\partial x}\left[\left(\frac{\rho h^{3}}{6 \eta}\right) \frac{\partial p_{h}}{\partial x}\right]+\frac{\partial}{\partial y}\left[\left(\frac{\rho h^{3}}{6 \eta}\right) \frac{\partial p_{h}}{\partial y}\right]=\left|U_{p}(\varphi)\right| \frac{\partial}{\partial x}(\rho h)+2 \frac{\partial}{\partial t}(\rho h)$

where, $U_{p}(\varphi)$ is the velocity of the piston at any crank angle [44]:

$U_{p}(\varphi)=-r \omega \sin \varphi\left\{1+\cos \varphi\left[\left(\frac{l}{r}\right)^{2}-\sin ^{2} \varphi\right]^{-\frac{1}{2}}\right\}$

The following inlet boundary conditions at the ring edges in the axial direction $x=0$ and $x=b$ are used:

$$
\left\{\begin{array}{l}
p_{h}(0, y)= \begin{cases}p_{i c} & \text { if } U_{p}(\varphi)>0 \\
p_{c c} & \text { if } U_{p}(\varphi)<0\end{cases} \\
p_{h}(b, y)= \begin{cases}p_{c c} & \text { if } U_{p}(\varphi)>0 \\
p_{i c} & \text { if } U_{p}(\varphi)<0\end{cases}
\end{array}\right.
$$


At the outlet Reynolds' exit boundary condition with a cavitation pressure is employed. Note that cavitation occurs only when the exit boundary falls within the ring face-width $\left(x_{c}<b\right)$ :

$\left\{\begin{array}{l}p_{h}\left(x_{c}, y\right)=p_{c} \\ \left.\frac{d p_{h}(x, y)}{d x}\right|_{x=x_{c}}=0\end{array}\right.$

In addition, at the edges of the gap in the incomplete fitted ring in the circumferential direction, the following boundary conditions at the ring edges $y=0$ and $y=L$ are used:

$p_{h}(x, 0)=p_{h}(x, L)=\frac{p_{i c}+p_{c c}}{2}$

A modified density-pressure relationship according to Yang et al [45] is used in order to also include its temperature dependency:

$\rho=\rho_{0}\left[1+\frac{a\left(p_{h}-p_{a t m}\right)}{1+b\left(p_{h}-p_{a t m}\right)}\right]\left[1-\chi\left(\theta-\theta_{0}\right)\right]$

in which the constants $a$ and $b$ are $6.0 \times 10^{-10}$ and $1.7 \times 10^{-9}$ respectively and the atmospheric pressure, $p_{a t m}=1.01325 \times 10^{5} \mathrm{~N} / \mathrm{m}^{2}$. The thermal expansivity of the lubricant, $\gamma$ and the lubricant density at atmospheric pressure, $\rho_{0}$ are given in Table 3.

Lubricant viscosity variation with pressure and temperature is obtained as [46]:

$\eta=\eta_{0} \exp \left(\alpha^{*} p_{h}\right)$

in which,

$\alpha^{*}=\frac{1}{p_{h}}\left[\ln \left(\eta_{0}\right)+9.67\right]\left\{\left(\frac{\theta-138}{\theta_{0}-138}\right)^{-S_{0}}\left(1+\frac{p_{h}}{1.98 \times 10^{8}}\right)^{Z}-1\right\}$

where, the pressure-viscosity index, $Z$ as well as the constant $S_{0}$ (both are assumed to be independent of temperature and pressure) are:

$Z=\frac{\alpha_{0}}{5.1 \times 10^{-9}\left[\ln \left(\eta_{0}\right)+9.67\right]}$

and

$S_{0}=\frac{\beta_{0}\left(\theta_{0}-138\right)}{\ln \left(\eta_{0}\right)+9.67}$

Lubricant bulk rheological properties are listed Table 3.

Table 3: Lubricant bulk rheological properties

\begin{tabular}{|c|c|c|}
\hline Parameter & Value & Unit \\
\hline Pressure-viscosity coefficient, $\alpha_{0}$ & $1 \times 10^{-8}$ & $\mathrm{~m}^{2} / \mathrm{N}$ \\
\hline Temperature-viscosity coefficient, $\beta_{0}$ & $4.0 \times 10^{-2}$ & - \\
\hline
\end{tabular}




\begin{tabular}{|c|c|c|}
\hline Thermal expansivity, $\gamma$ & $1 \times 10^{-3}$ & $\mathrm{~K}^{-1}$ \\
\hline Eyring shear stress, $\tau_{0}$ & $2 \times 10^{6}$ & $\mathrm{~Pa}$ \\
\hline Density, $\rho$ & $849.7 @ 15^{\circ} \mathrm{C}, 833.8 @ 40^{\circ} \mathrm{C}$ & $\mathrm{kg} / \mathrm{m}^{3}$ \\
\hline Kinematic viscosity, $v$ & $59.99 @ 40^{\circ} \mathrm{C}, 9.590 @ 100^{\circ} \mathrm{C}$ & $\times 10^{-6} \mathrm{~m}^{2} / \mathrm{s}$ \\
\hline
\end{tabular}

The ring/liner gap profile can generally be presented as follows:

$h(x, y, t)=h_{m}(t)+h_{s}(x)+\delta(x, y, t)+\Delta_{s}(y, t)+\Delta_{t h}(y, t)+\Delta_{d}(y, t)$

in which, the total gap is composed of several elements: $h_{m}$ represents variations of the minimum film thickness with time. The parameter $h_{s}$ describes the ring axial face-width profile. The parameter $\delta$ is the local pressure-induced deformation, whilst $\Delta_{s}, \Delta_{t h}, \Delta_{d}$ represent the 'global' elastostatic, thermoelastic and elastodynamic deformation of ring-liner conjunction. The initial distortion which exist in a fitted liner to the engine block or due to the tightening the cylinder head bolts and provide a non-zero value for $\Delta_{s}$ [11]. A thermoelastic analysis may provide the thermally deformed bore (or ring) profile for which the emerging gap can be included in $\Delta_{t h}$, whilst $\Delta_{d}$ takes into account the change in the ring/liner gap due to deformations caused as a result of mechanical vibrations of either bore or ring under application of transient loads.

It is shown that for most engines, particularly gasoline variety with insufficiently high pressures elastohydrodynamic regime of lubrication does not occur (i.e. negligible localised deformation, $\delta \approx 0$ ) [5-9]. Global elastostatic deformation and ring-bore conformability issues have been sufficiently addressed by others [4, 11, 47]. In addition, incorporation of thermal and global dynamic deformation is beyond the scope of the current study. Therefore, equation (15) simplifies to:

$h(x, y, t)=h_{m}(t)+h_{s}(x)$

The new ring's axial face-width profile and those under various states of wear (Figure 4) are described using a $6^{\text {th }}$ order polynomial (hexanomial) curve fit of the measured data:

$h_{s}(x)=a x^{6}+b x^{5}+c x^{4}+d x^{3}+e x^{2}+f x+g$

The coefficients for these polynomial functions are given in Table 4.

Table 4: Coefficients of polynomials describing the ring profiles

\begin{tabular}{|c|c|c|c|c|c|c|c|}
\hline Coefficient & $\boldsymbol{a}$ & $\boldsymbol{b}$ & $\boldsymbol{c}$ & $\boldsymbol{d}$ & $\boldsymbol{e}$ & $\boldsymbol{f}$ & $\boldsymbol{g}$ \\
\hline New Ring & 427.9 & -1455.8 & 1971.4 & -1354.4 & 544.57 & -150.49 & 25.30 \\
\hline Run-in Ring & -197.16 & 578.85 & -583.44 & 200.37 & 56.366 & -62.709 & 13.857 \\
\hline Embedded Ring & -6.493 & -49.845 & 143.22 & -98.541 & 27.351 & -17.338 & 7.4986 \\
\hline
\end{tabular}

It should be noted that the coefficients are based on that the millimetre and micrometre units are used for $x$ and $h_{s}$ in the given polynomial equation above, respectively.

Having obtained the film thickness, the contribution to friction due to viscous shear of the lubricant film is calculated as: 
$f_{v}=\int \vec{\tau}_{v} d A$

where: $\vec{\tau}_{v}=\left| \pm \frac{h}{2} \vec{\nabla} p-\Delta \vec{V} \frac{\eta}{h}\right|$

and: $\Delta \vec{V}=U(\varphi), \vec{\nabla} \equiv\left(\frac{\partial}{\partial x} \hat{\imath}+\frac{\partial}{\partial y} \hat{\jmath}\right)$

Therefore, at any instant of time (crank-angle), the total friction becomes:

$f_{t}=f_{b}+f_{v}$

Finally, the key parameter of interest is the frictional power loss:

$P_{l}=f_{t}|U(\varphi)|$

where, the piston speed is given in equation (11)

\subsection{Method of Solution}

At any crank angle, a Point Successive Over-Relaxation (PSOR) iterative method is used [48]. At any instant of time (crank-angle position) an initial value for the minimum film thickness, $h_{m}$ in equation (21) is assumed. The iterative procedure includes simultaneous solution of equations (10), (15), (16) and (21), where the equilibrium condition in equation (5) needs to be satisfied within a specified limit [11]. If the condition is not met the initial assumed gap is altered through relaxation technique and the entire solution procedure is repeated. This procedure is detailed in Rahmani et al [11]. When convergence is achieved at any instant of time (crank-angle position), the analysis advances to the next crank position (simulation time is advanced), with the new contact kinematics determined by equation (11). The solution step size in the current analysis corresponds to an incremental advance of one degree crank-angle.

\section{RESULTS AND DISCUSSION}

Numerical predictions are made in respect of all the aforementioned three rings, representing the various stages of the ring life. In particular, simulations are carried out at the engine speed of $1500 \mathrm{rpm}$ and bulk oil temperature of $120^{\circ} \mathrm{C}$. These conditions correspond to the vehicle under crawling city driving condition, representative of hot steady state cycle in the New European Driving cycle for emission testing. Figure 7 shows the measured combustion pressure curve for the aforementioned conditions. The peak pressure at 62 Bars occurs at the detonation point $20^{\circ}$ crank angle past the top dead centre (TDC) in the case of this 4-stroke V12 engine. 


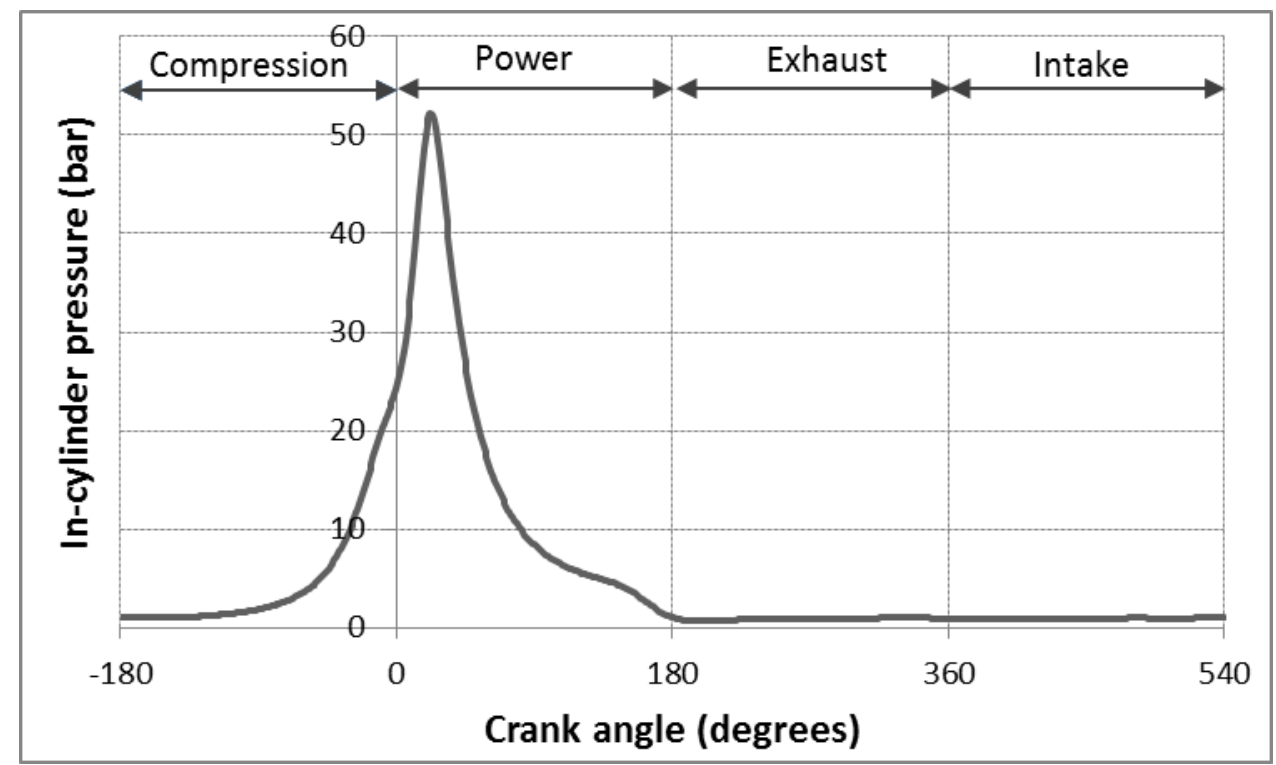

Figure 7: Variation of the pressure inside the combustion chamber with crank angle at various engine speeds at 1500 rpm

Figure 8 shows the predicted film thickness for the three ring profiles (various stages of wear) shown in Figure 4. As expected, in all cases the minimum film thickness occurs in the compression stroke in reversal at the TDC to the power stroke (crank angle of $0^{\circ}$ ) and during this stroke. During this part of the engine cycle, the lubricant film has the least thickness when the ring is new on account of its better conformity to the cylinder liner surface. As the process of wear ensues, a larger clearance emerges and, therefore, both the worn rings enjoy a slightly enhanced conjunctional film thickness. In the parts of the engine cycle explained thus far, a mixed regime of lubrication is encountered as the film thickness is insufficient to completely keep the counterfaces apart. For example, the oil film parameter, $\lambda$, is 1.41 at the maximum combustion pressure for the new ring and 1.18 for that denoted as the embedded ring state. Elsewhere during the engine cycle the film thickness increases in direct proportion to the piston speed: $h \propto U_{p}(\varphi)$, given by equation (11). This indicates the prevalent hydrodynamic regime of lubrication.

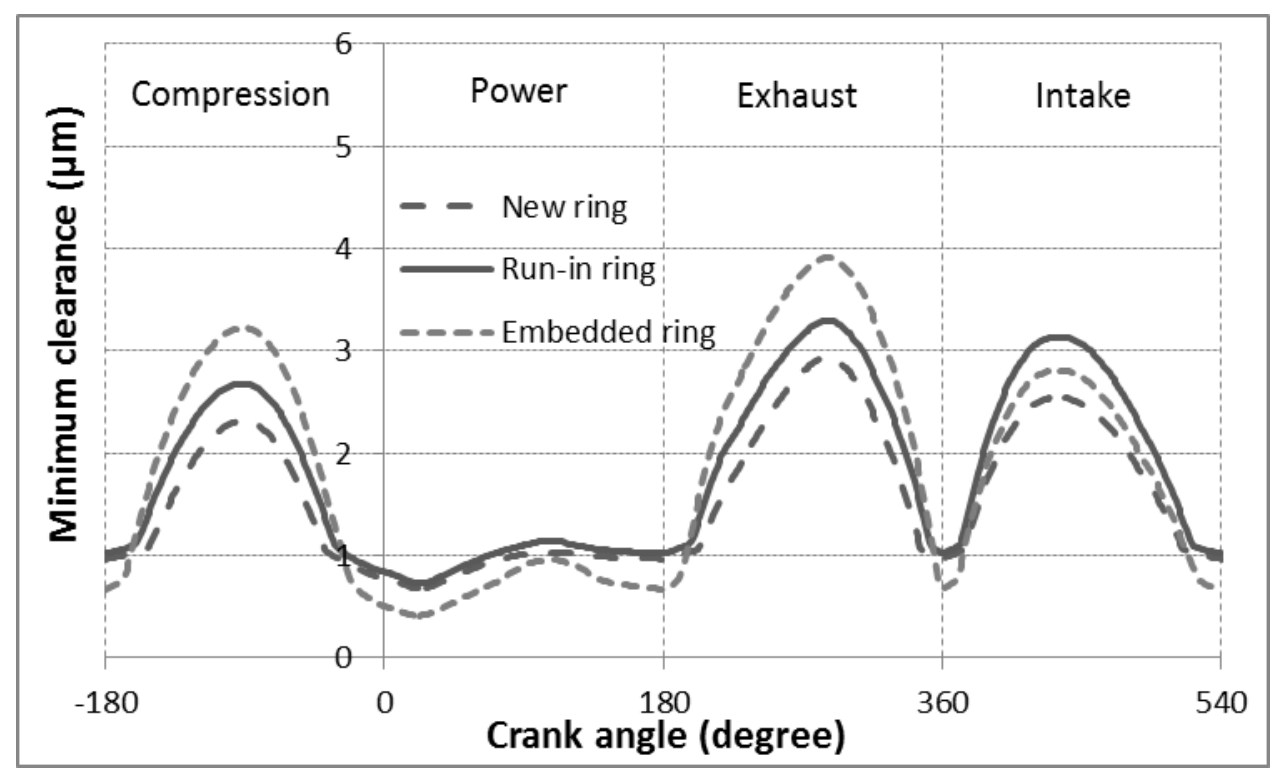


DOI: $10.1177 / 1468087413519783$

(Accepted Version)

Figure 8: Minimum clearance for top compression ring at its different life stages during an engine cycle at $1500 \mathrm{rpm}$ and $120^{\circ} \mathrm{C}$

Figure 9 shows that the major contribution to friction arises in the same part of the engine cycle as the minimum film thickness occurs (at the transition from the compression to the power stroke during piston reversal at the TDC and extends just beyond the detonation point. The inset to the figure illustrates that the main contribution to friction in the aforementioned region is due to boundary interactions. Naturally, a new ring with the intact hard wear resistant coating presents greater asperity level shear strength, $\varsigma$ and a larger Tabor parameter $N \beta \sigma$ than the worn rings. Thus, a larger boundary friction contribution $f_{b}$ is predicted for the new ring. This finding is in line with observations in practice, where a new ring gradually wears both in topographical terms and geometrical profile as shown in Figure 4. 


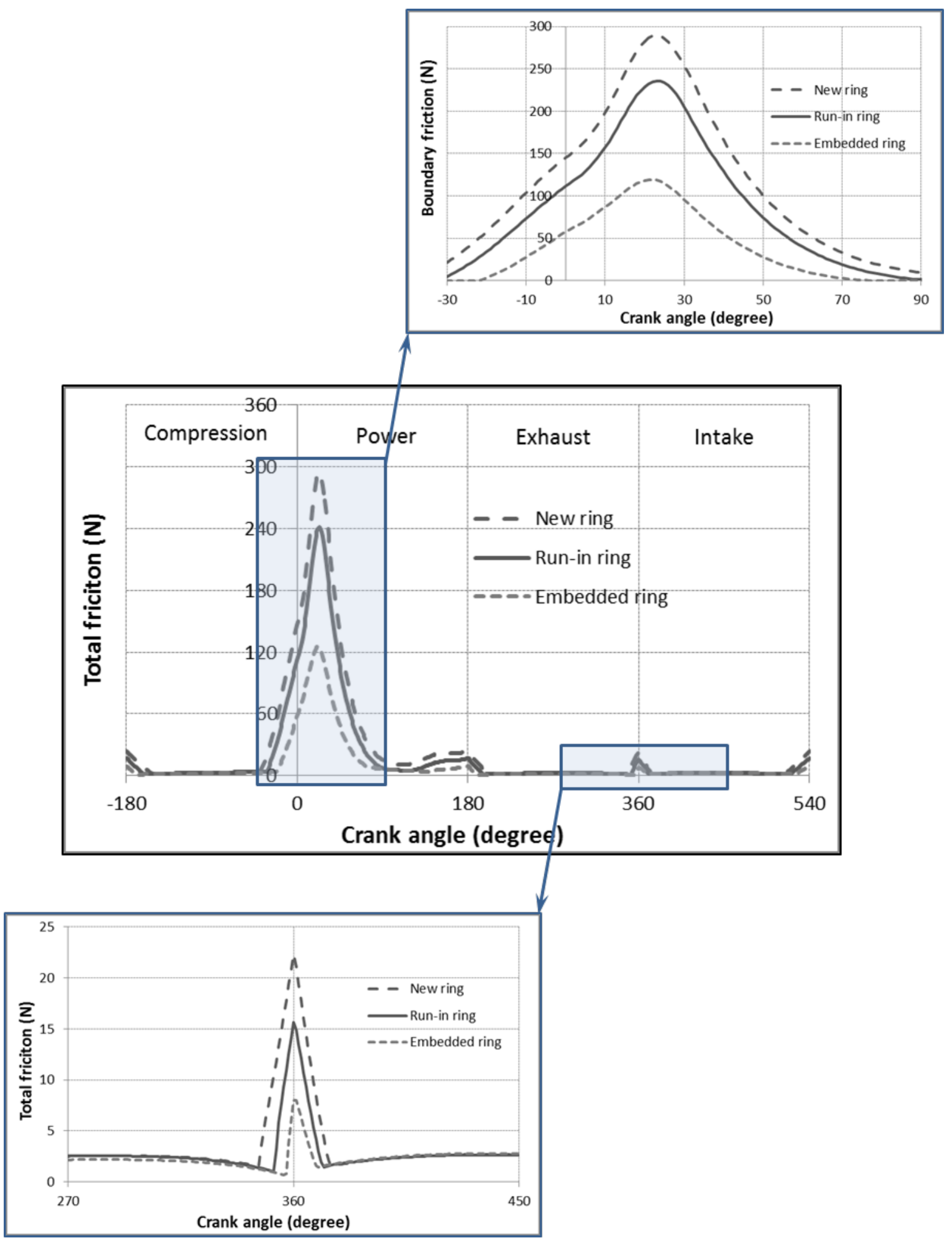

Figure 9: Generated friction for top compression ring at various stages of its wear at $1500 \mathrm{rpm}$ and $120^{\circ} \mathrm{C}$

Although boundary friction indicates that a new ring generates more friction than the worn rings through sharper asperity slopes and a larger value of $s$, viscous friction also varies with different ring wear state because of the evolving topography as well as conjunctional geometry. Therefore, the transient nature of ring-bore tribology is best appreciated using the 
idea of a Stribeck chart, where the predicted coefficient of friction; $\mu=f_{t} / W$ (equations (5) and (25)) is plotted against the Stribeck's lubricant service parameter: $\eta U_{p}(\varphi) / p \sigma$ for the region of high generated pressures (from mid-stroke compression to mid-stroke expansion in the power stroke). Figure 10 (a-c) shows the march of coefficient of friction for the three different ring states investigated in the current study. It is noteworthy that $\mu$ reaches the relatively high value of 0.17 in the region of TDC reversal to just beyond the maximum combustion pressure for the case of the new ring. This indicated significant boundary interactions. Note that if $\mu \approx \varsigma$, a total boundary regime of lubrication would ensue. With wear of the hard wear resistant coating the coefficient of friction progressively reduces in the aforementioned region. Beyond the region TDC reversal-to-maximum chamber pressure, and during the power stroke, the change in coefficient of friction with state of ring wear is much less pronounced. The regime of lubrication is firmly within mixed hydrodynamics. In the compression stroke the coefficient of friction is mainly that due to the viscous shear of a lubricant film, which reduces gradually as the piston speed decreased towards the TDC and with it the viscous shear stress (equation (23)).

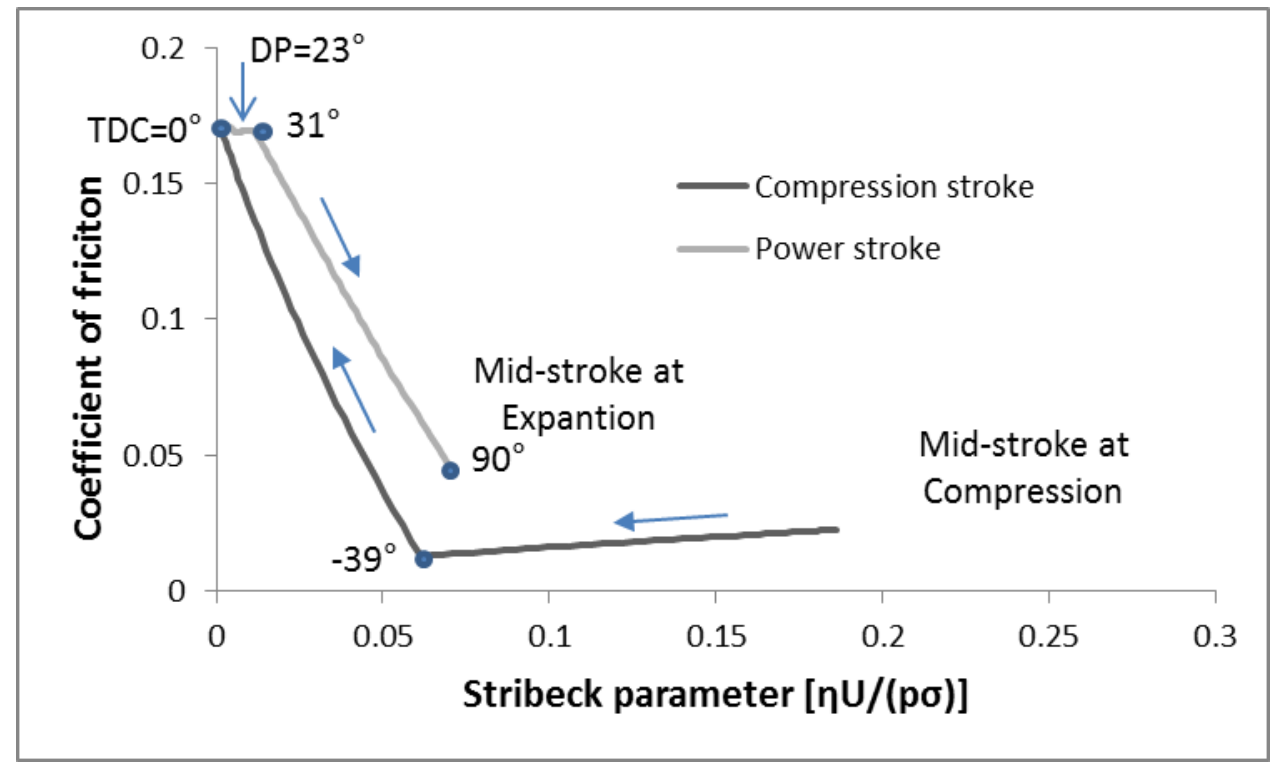

(a)- New ring 
DOI: $10.1177 / 1468087413519783$

(Accepted Version)

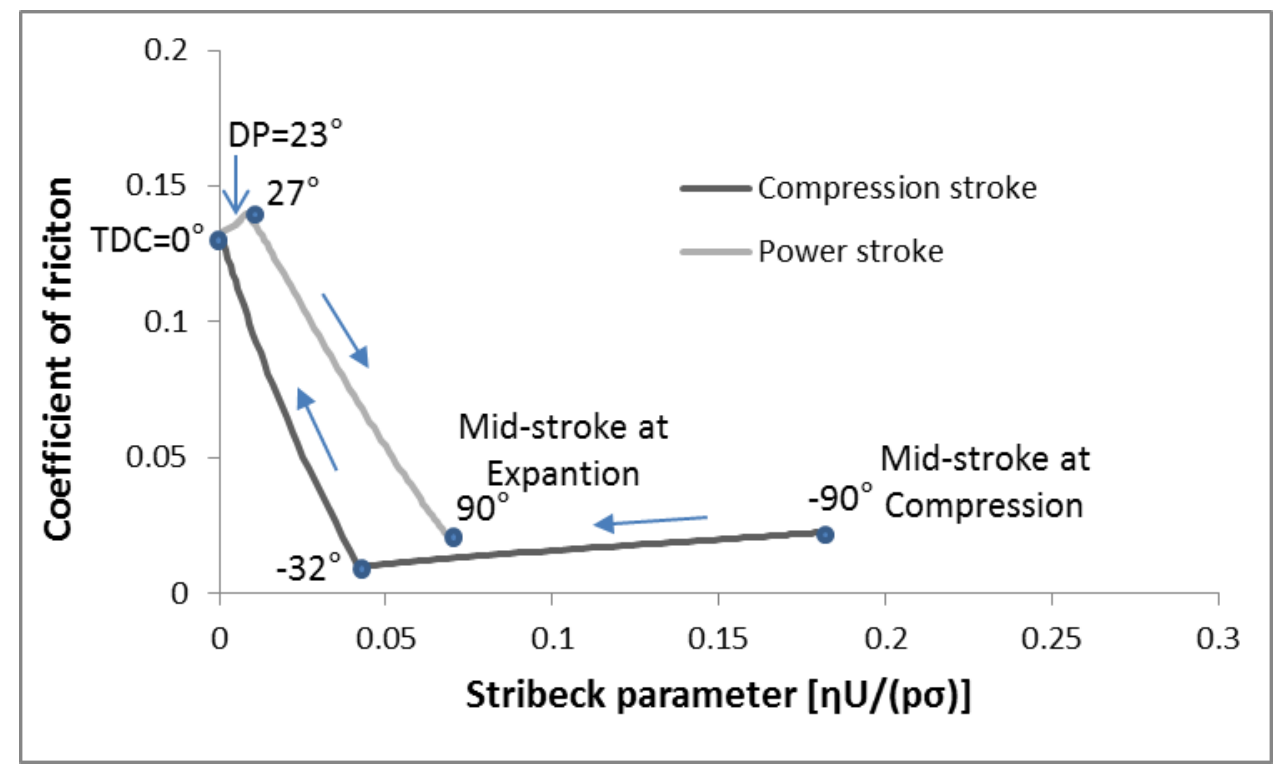

(b)- Run-in ring

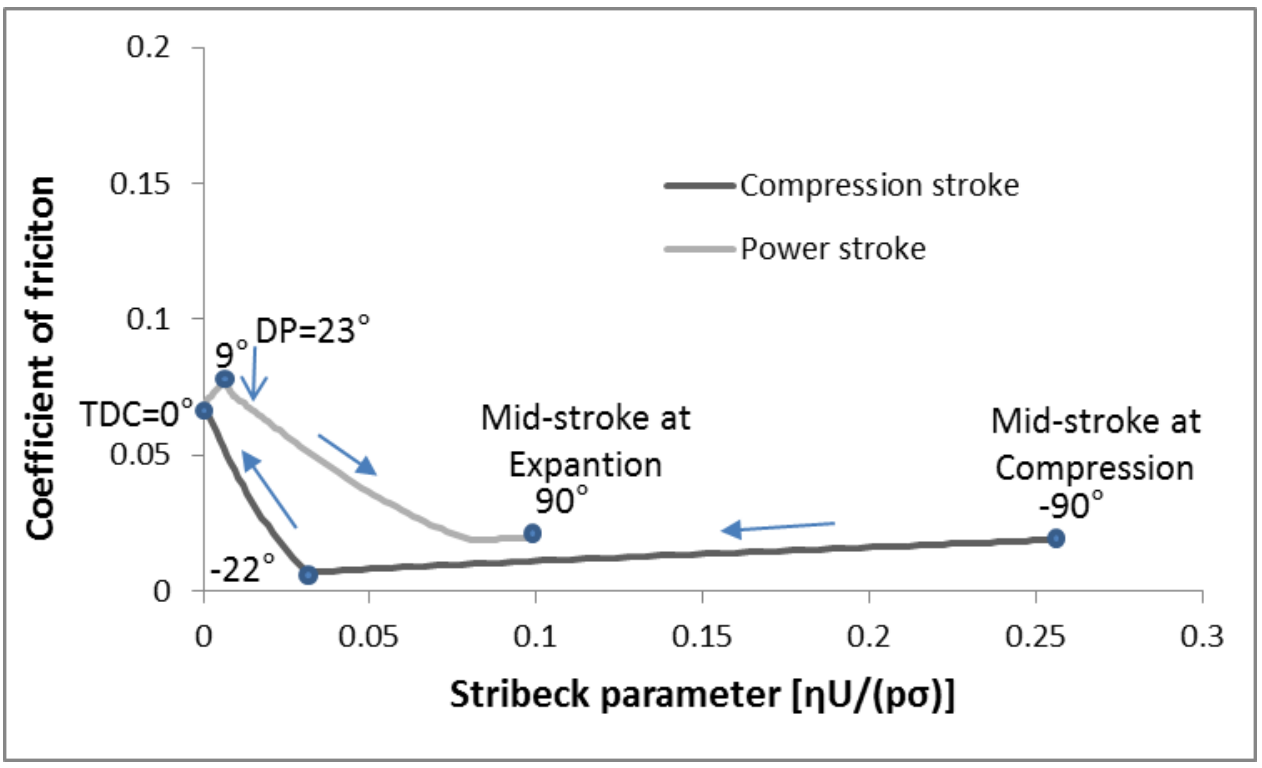

(c)- Embedded ring

Figure 10: Transient nature of coefficient of friction at $1500 \mathrm{rpm}$ and $120^{\circ} \mathrm{C}$

In the current study the progressively more worn rings present a lower value of $\varsigma$, thus boundary friction indicated by Figures 9 and 10. This could lead to the counter-intuitive conclusion that a worn ring would provide better performance. However, the main function of the compression ring is its sealing ability which is gradually breached with its progressive wear. This is evident from the lubricant flow rate through the ring-bore conjunction for the rings' studied here (Figure 11). It is clear that the embedded ring with long term use allows a significantly higher flow rate. In fact, in practice this would result in a number of untoward effects, rendering the embedded ring the status of end-of-life. These effects include oil loss, blow-by and lubricant degradation/contamination from ingression of combustion products, particularly soot. 


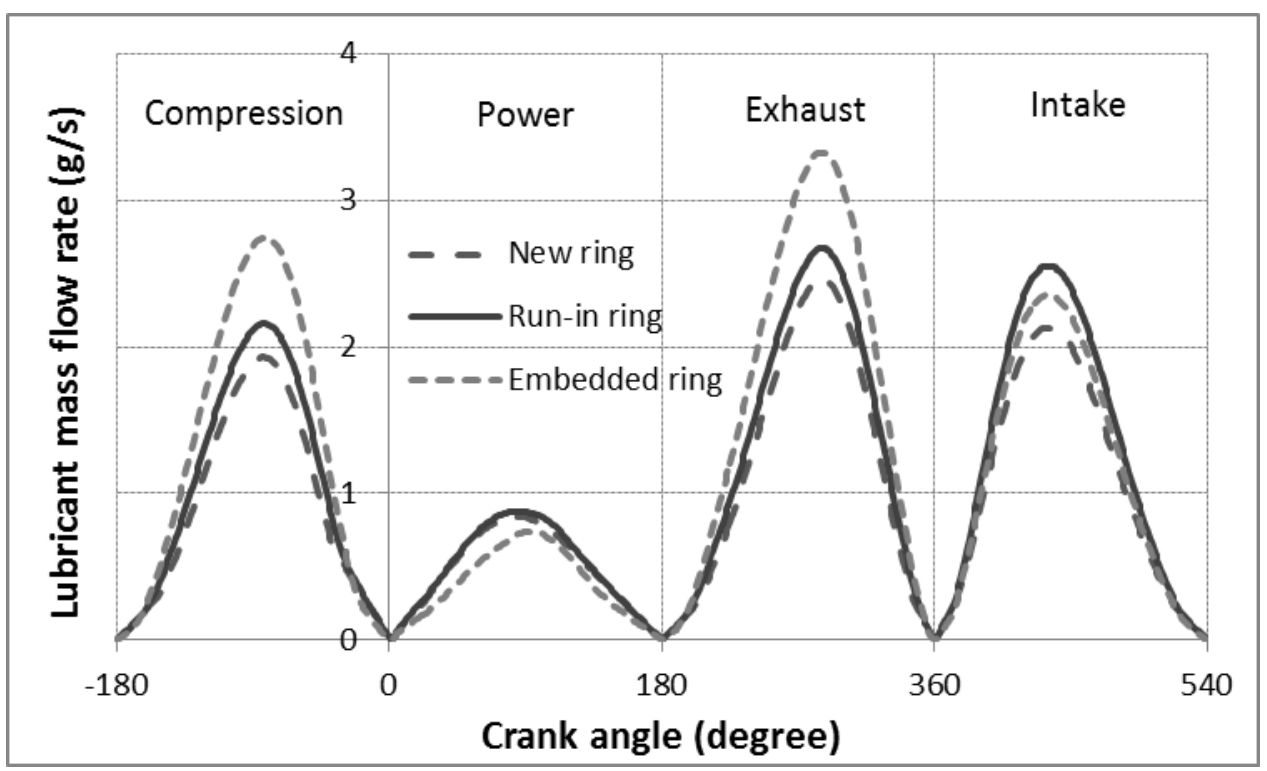

Figure 11: Lubricant mass flow rate calculated at the middle cross-section of the ring at $1500 \mathrm{rpm}$ and $120^{\circ} \mathrm{C}$

\section{CONCLUSIONS}

Predictions show that ring-bore friction is dominated by mixed and boundary regimes of lubrication in the transition from the compression stroke to the power stroke and extend beyond the detonation point. Elsewhere a lubricant film of sufficient thickness is formed to attain low friction hydrodynamics. It is also shown that boundary contribution to overall friction is quite significant in the aforementioned zone with the engine cycle and accurate predictions need precise measurement of surface topography and shear strength of often coated surfaces.

One of the important findings of the current study is the effect of wear of ring coating upon friction and sealing performance of the top compression ring. There are some practical implications from the findings. The ring and/or liner/bore surfaces are usually furnished with hard wear resistant coatings such as the plasma sprayed Ni-Cr-Mo ring land coating, described above. Progressively, coatings of even higher hardness and smoother surfaces are used (such as diamond like coating; DLC) with the implication of a greater value of $\varsigma$, yielding higher boundary friction. It should be noted that for hard wear resistant coatings asperity friction through ploughing action is mainly by brittle fracture [23]. The friction in these cases is a function of hardness rather than elastic ploughing of asperities. The results here show that it is far better to reduce the shear strength of wear resistant coatings, whilst reducing surface interactions in the TDC-detonation point region with surface etching of the liner. This is described in some detail by Rahnejat et al [49] and Etsion and Sher [50].

There are certain number of shortcomings in the current analysis; chiefly the assumption of a fully flooded inlet and disregarding the temperature rise of the lubricant at the inlet nib to the contact. The former is unlikely to be the case, particularly during the latter parts of the compression stroke where a supply of lubricant upon the bore/liner surface is not assured. A resulting starved inlet would lead to an even thinner film at the TDC reversal, promoting further boundary interactions. The latter requires a thermal balance analysis for flow through the contact. A recent analysis by Morris et al [51] shows that temperature rise due to inlet 
shear heating of the lubricant by convected heat into the bulk lubricant flow is considerably more important than a modest rise through lubricant viscous shear in the contact because of short transit time at any instant of time. Therefore, the current analysis is considered as reasonable when steady state thermal balance is reached, with the inlet lubricant temperature being the same as the contiguous solids. Nevertheless, the inclusion of inlet boundary starvation and thermal mixing at the nib of the contact represent the future direction of the analytical approach presented here.

\section{ACKNOWLEDGMENT}

The authors would like to express their gratitude to the Engineering and Physical Sciences Research Council (EPSRC) for the sponsorship of this research under the Encyclopaedic Program Grant (www.encyclopaedic.org). Thanks are also extended to the other partner organisations, particularly in this instance to Aston Martin Lagonda for both its financial and technical support.

\section{NOMENCLATURE}

A

Apparent contact area

$A_{a}$

Asperity contact area

$B$

Cylinder bore diameter

$b$

Ring face width

$E$

Young’s modulus of elasticity

$E^{\prime}$

Composite Young's modulus of elasticity

$F_{2}, F_{5 / 2}$

Statistical functions

$f_{b}$

Boundary friction

$F_{t}$

Ring tension force

$f_{t}$

Total friction

$F_{v}$

Viscous friction

G

Shear modulus (Appendix)

$h$

Ring/bore total gap profile

$h_{s}$

Ring profile

$k_{N}$

Normal spring constant (Appendix)

$k_{T}$

Torsional spring constant (Appendix) 


\begin{tabular}{|c|c|}
\hline$l$ & Connection rod length \\
\hline$L$ & Length of the cantilever (Appendix) \\
\hline$m$ & Spectral moment \\
\hline$N$ & Density of asperity peaks \\
\hline$p_{0}$ & Atmospheric pressure \\
\hline$p_{c}$ & Cavitation pressure \\
\hline$p_{e}$ & Elastic pressure \\
\hline$p_{h}$ & Hydrodynamic pressure \\
\hline$p_{g}$ & Gas pressure \\
\hline$P_{l}$ & Power loss \\
\hline$r$ & Crank radius \\
\hline$R$ & Length (height) of the cantilever tip (Appendix) \\
\hline$S_{0}$ & Roeland temperature-viscosity constant \\
\hline$S$ & Sensitivity of AFM photodiode (Appendix) \\
\hline$S_{N}$ & Normal Sensitivity of AFM photodiode (Appendix) \\
\hline$S_{T}$ & Torsional sensitivity of AFM photodiode (Appendix) \\
\hline$T$ & Torsional force (Appendix) \\
\hline$U_{p}$ & Piston velocity \\
\hline$V$ & Velocity \\
\hline$W$ & Total load \\
\hline$W_{a}$ & Asperity load capacity \\
\hline$W_{h}$ & Hydrodynamci pressure \\
\hline$x, y$ & Cartesian coordinates \\
\hline$x_{c}$ & Cavitation (rupture) point \\
\hline$z(x)$ & Roughness profile \\
\hline
\end{tabular}


Pressure-viscosity constant

\title{
Superscripts
}

\author{
1,2 \\ Surface 1 or 2 \\ Composite
}

c

\section{Subscripts}

Ambient (Atmospheric) conditions

Surface 1 or 2

2,4

The second and forth moments

ic In-cylinder

$C C$

Crank case

\section{Greek symbols}

$\alpha^{*} \quad$ Modified pressure-viscosity coefficient

$\alpha_{0} \quad$ Pressure-viscosity coefficient

$\beta \quad$ Average asperity summit radius

$\beta_{0} \quad$ Temperature-viscosity coefficient

$\gamma \quad$ Thermal expansivity

$\Delta_{d} \quad$ Elastodynamic deformation

$\Delta_{s} \quad$ Elastostatic (initial) deformation

$\Delta_{t h} \quad$ Thermal deformation

$\Delta I_{N} \quad$ Signal from normal AFM tip deflection (Appendix)

$\Delta I_{T} \quad$ Signal from torsional AFM tip deflection (Appendix)

$\Delta F_{N} \quad$ Normal force (Appendix)

$\Delta F_{T} \quad$ Torsional force (Appendix)

$\delta \quad$ Local elastic Hertzian deformation

$\eta \quad$ Dynamic viscosity 
International Journal of Engine Research (February 2014)

DOI: $10.1177 / 1468087413519783$

(Accepted Version)
Temperature
Stribeck oil parameter (oil film ratio)
$v$
Poisson ratio
$\rho$
Density
$\varsigma$
Coefficient of boundary shear strength
$\sigma$
Composite surface roughness of the contacting surfaces
$\sigma_{\mathrm{s}}$
Standard deviation of asperity heights
$\tau_{0}$
Eyring shear stress
$\tau_{v}$
Viscous shear
$v$
Kinematic viscosity
$\varphi$
Crank angle
$\psi$
AFM-specific overall calibration factor (Appendix)
$\omega$
Engine rotational speed

\section{Abbreviations}

AFM

Atomic Force Microscope

BDC

Bottom Dead Centre

DLC

Diamond-Like Carbon

EHL

Elastohydrodynamic

FFM

Friction Force Microscope

FM

Lateral Force Microscope

GT

Greenwood and Tripp

HSS

High Speed Steel

RMS

Root Mean Square

TDC

Top Dead Centre

TMR

Trace Minus Retrace (Appendix) 
International Journal of Engine Research (February 2014)

DOI: $10.1177 / 1468087413519783$

(Accepted Version)

WOT Wide Open Throttle

\section{REFERENCES}

[1]- Fitzsimons, B., "Introduction to the importance of fuel efficiency and role of the Encyclopaedic research project”, Proc. IMechE Seminar on A Drive for Fuel Efficiency, 2011, Loughborough University, Loughborough, UK

[2]- Furuhama, S., “A dynamic theory of piston-ring lubrication, 1st report-calculation”, Bull. JSME 2(7), 1959, pp. 423-428

[3]- Dowson, D., Ruddy, B.L. and Economou, P.L., 'The elastohydrodynamic lubrication of piston rings', Proc. Roy. Soc. London, Series A, Mathematical and Physical Sciences, 386 (1791), 1983, pp. 409-430

[4]- Ma, M.-T., Sherrington, I. and Smith, E.H., 'Analysis of lubrication and friction for a complete piston-ring pack with an improved oil availability model - Part 1: circumferentially uniform film', Proc. IMechE, Part J: J. Engng. Trib., 211, 1997, pp. 1-15

[5]- Akalin, O. and Newaz, G.M., 'Piston ring-cylinder bore friction modeling in mixed lubrication regime, Part I - analytical results’, Trans. ASME, Series F: J. Trib., 123, 2001, pp. 211-218

[6]- Bolander, N.W., Steenwyk, B.D., Sadeghi, F. and Gerber, G.R., 'Lubrication regime transitions at the piston ring-cylinder liner interface', Proc. IMechE. Part J: J. Engng. Trib., 219, 2005, pp. 19-31

[7]- Mishra, P.C., Balakrishnan, S. and Rahnejat, H., 'Tribology of compression ring-tocylinder contact at reversal', Proc. IMechE, Part J: J. Engng. Trib., 222, 2008, pp. 815-826

[8]- Mishra, P.C., Rahnejat, H. and King, P.D., 'Tribology of the ring-bore conjunction subject to a mixed regime of lubrication', Proc. IMechE, Part C: J. Mech. Engng. Sci., 223(4), 2009, pp. 987-998

[9]- D’Agostino, V. and Senatore, A., "Fundamentals of lubrication and friction of piston ring contact”, in Rahnejat, H. (Ed.) Tribology and dynamics of engine and powertrain: Fundamentals, Applications and Future trends, Woodhead Publishing, Cambridge, 2010, pp. 343-385, ISBN 978-1-84569-361-9

[10]- Furuhama, S. and Sasaki, S., 'New device for the measurement of piston frictional forces in small engines', SAE Paper No. 831284, 1983

[11]-Rahmani, R., Theodossiades, S., Rahnejat, H. and Fitzsimons, B., “Transient elastohydrodynamic lubrication of rough new or worn piston compression ring conjunction with an out-of-round cylinder bore”, Proc IMechE Part J: J Engineering. Tribology, 226(4), 2012, pp. 284-305

[12]- Akalin, O. and Newaz, G.M., "Piston ring-cylinder bore friction modeling in mixed lubrication regime, Part II - correlation with bench test data”, Trans. ASME, Series F: J. Trib. 123, 2001, pp. 219-223.

[13]- Abd Al-Samieh, M. F. and Rahnejat, H., "Ultra-thin lubricating films under transient conditions”, J. Phys., D: Appl. Phys., 34, 2001, pp. 2610-2621.

[14]- Chong, W.W.F., Teodorescu, M. and Rahnejat, H., "Effect of lubricant molecular rheology on formation and shear of ultra-thin surface films", J. Physics, D: Appl. Phys., 44(16), 2011, 165302 
[15]- Greenwood, J.A. and Tripp, J.H., “The contact of two nominally flat rough surfaces, Proc. IMechE, J. Mech. Engng. Sci., 185, 1971, pp. 625-634.

[16]- Erdemir, A., "Review of engineered tribological interfaces for improved boundary lubrication” Tribology. Int. 38, 2005, pp. 249-56.

[17]- Chong, W.W.F., Teodorescu, M. and Rahnejat, H., "Physio-chemical hydrodynamic mechanism underlying the formation of thin adsorbed boundary films", Faraday Discuss., 2012, DOI: 10.1039/C2FD00118G

[18]- Balakrishnan, S. and Rahnejat, H., "Isothermal transient analysis of piston skirt-tocylinder wall contacts under combined axial, lateral and tilting motion”, J. Phys., D: Appl. Phys., 38, 2005, 787

[19]- Kushwaha, M., Rahnejat, H. and Jin, Z.M., "Valve-train dynamics: a simplified triboelasto-multi-body analysis”, Proc. IMechE, J. Multi-body Dyn., 214(2), 2000, pp. 95-110

[20]- Kiuru, M. and Alakoski, E., “Low sliding angles in hydrophobic and oleophobic coatings prepared with plasma discharge method”, Mat. Letts., 58(160), 2004, pp. 2213-2216

[21]- Howell-Smith, S.J., Tribological optimisation of the internal combustion engine piston to bore conjunction through surface modification ${ }_{2} \mathrm{PhD}$ Thesis, Loughborough University, November 2010

[22]- Morris, N., Rahmani, R., Rahnejat, H., P.D. King and Fitzsimons, B., "The influence of piston ring geometry and topography on friction”, Proc. IMechE, J. Engng. Trib., 2012, in press

[23]- Gohar, R. and Rahnejat, H., Fundamentals of Tribology, Imperial College Press, London, 2008

[24]- Fuller, K.N.G. and Tabor, D., "The Effect of Surface Roughness on the Adhesion of Elastic Solids”, Proc. Roy. Soc., Lond. A 30, 345, 1975, pp. 327-342

[25]- P. Prokopovich, S. Theodossiades, H. Rahnejat and D. Hodson, "Friction in ultra-thin conjunction of valve seals of pressurised metered dose inhalers”, Wear, 268, 2010, pp. 845852

[26]- Arcoumanis, C., Ostovar, P. and Mortimer, R., "Mixed lubrication modelling of Newtonian and shear thinning liquids in a piston-ring configuration”, SAE Pap. No. 972924, 1997.

[27]- Mate, C.M., “Atomic-scale friction of a tungsten tip on a graphite surface”, Phys. Rev. Letts. 59(17), 1987, pp.1942-1946.

[28]- Kaneko, R. and Miyamoto, T., "Friction and adhesion forces on magnetic disk surfaces”, IEEE Trans. on Magnetics, 24(6), 1988, pp. 2641-2643.

[29]- Landman, U., Luedtke, W.D. and Nitzan, A., "Dynamics of tip-substrate interactions in atomic force microscopy”, Surface Sci. Letts., 210, 1989, L177-L184.

[30]- Meyer, E., Heinzelmann, H., Grutte, P., Jung, TH., Hidber. H.-R., Rudin, H. and Guntherodt, H.-J., “Atomic force microscopy for the study of tribology and adhesion”, Thin Solid Films, 181, 1989, pp. 527-544 
[31]- Meyer, G. and Amer, N.M., "Simultaneous measurement of lateral and normal forces with an optical beam deflection atomic force microscope”, Appl. Phys. Letts., 57, 1990, pp. 2089-2091

[32]-Tomanek, D., "Calculation of an atomically modulated friction force in atomic-force microscopy”, Europhys. Lett., 15(8), 1991, pp. 887-892

[33]- Ruan, J.-A. and Bhushan, B., “Atomic-scale friction measurements using friction force microscopy: Part I-General: principles and new measurement techniques”, Trans. ASME, J. Tribology, 116(2), 1994, pp. 378-388

[34]- Warmack, R.J., Zheng, X.Y. and Allison, D.P., "Friction effects in the deflection of atomic force microscope cantilevers”, Rev. Sci. Instrum., American Institute of Physics, 65(2), 1996, pp. 394-399

[35]- Ogletree, D.F., Carpick, R.W. and Salermon, M., "Calibration of frictional forces in atomic force microscopy”, Rev. Sci. Instrum., American Institute of Physics, 67(9), 1996, pp. 3298-3306

[36]- Buenviaje, C.K., Ge, S.-R., Rafaillovich, M.H. and Overney, R.M., “Atomic force microscopy calibration methods for lateral force, elasticity, and viscosity”, Mat. Res. Soc. Symp. Proc. 522, 1998, pp. 187-192

[37]- Baker, C.E., Theodossiades, S., Rahnejat, H. and Fitzsimons, B. "Influence of in-plane dynamics of thin compression rings on friction in internal combustion engines”, Trans. ASME, J. Engng. for Gas Turbines \& Power, 134, 2012, DOI: 10.1115/1.4006690

[38]- Teodorescu, M., Taraza, D., Henein, N.A. and Bryzik, W., 'Simplified elastohydrodynamic friction model of the cam-tappet contact', SAE Paper No. 2003-01-0985, 2003

[39]- Briscoe, B.J. and Evans, D.C.B., “The shear properties of Langmuir-Blodgett layers”, Proc. Roy. Soc., Series A: Mathematical and Physical Science, 380(1779), 1982, pp. 389-407

[40]- Bowden, F.P. and Tabor, D., "The friction and lubrication of solids", Clarendon Press, Oxford, 1950

[41]- Johnson, K.L., Kendall, K. and Roberts, A.D., "Surface energy and the contact of elastic solids”, Proc. Roy. Soc., A, 345, 1975, pp. 327-342

[42]- Teodorescu, M. and Rahnejat, H., "Dry and wet nano-scale impact dynamics of rough surfaces with or without a self-assembled mono-layer", Proc. IMechE, J. Nanoengineering \& Nanosystems, 221, 2008, pp. 49-58

[43]- Chong, W.W.F., Teodorescu, M. and Rahnejat, H. "Nanoscale elastoplastic adhesion of wet asperities”, Proc. IMechE, Part J: J. Engineering Tribology, DOI:

10.1177/1350650112472142, 2013

[44]- Rahnejat, H. Multi-body Dynamics: Vehicles, Machines and Mechanisms, Professional Engineering Publishing (IMechE), Bury St Edmunds, UK, and SAE, Warrendale, Pa, USA, 1998

[45]- Yang, P., Cui, J., Jin, Z.M. and Dowson, D., 'Transient elastohydrodynamic analysis of elliptical contacts. Part 2: thermal and Newtonian lubricant solution', Proc. IMechE, Part J: J. Engineering Tribology, 219, 2005, pp. 187-200

[46]- Houpert, L., "New results of traction force calculations in elastohydrodynamic contacts”, Trans ASME, J. Tribology, 107, 1985, pp. 241-248 
[47]- Hu, Y., Cheng, H.S., Arai, T., Kobayashi, Y. and Aoyama, S., "Numerical simulation of piston ring in mixed lubrication - A non-axisymmetrical analysis", Trans ASME, J. Trib. 116, 1994, pp. 470-478

[48]- Hoffmann, K.A. and Chiang, S.T. Computational fluid dynamics for engineers, Vol. I. Wichita, KS, USA: A Publication of Engineering Education System, 1993

[49]- Rahnejat, H., Balakrishnan, S., King, P.D. and Howell-Smith, S. "In-cylinder friction reduction using a surface finish optimization technique”, Proc. IMechE, Part D: J. Auto. Engng., 220(9), 2006, pp. 1309-1318

[50]- Etsion, I. and sher, E. "Improving fuel efficiency with laser surface textured piston rings”, Trib. Int., 42(4), 2009, pp. 542-547

[51]- Morris, N., Rahmani, R., Rahnejat, H., King, P.D. and Fitzsimons, B. “Tribology of piston compression ring conjunction under transient thermal mixed regime of lubrication", Trib. Int., http://dx.doi.org/10.1016/j.triboint.2012.002

[52]- Ahimou, F., Semmens, M. J., Novak, P. J. and Haugstad, G., "Biofilm cohesiveness measurement using a novel atomic force microscopy methodology", Applied and

Environmental Microbiology, 73(9), 2007, pp. 2897-2904

\section{APPENDIX A: Procedure for measurement of coefficient of boundary shear strength using AFM}

To accurately predict boundary friction the coefficient of boundary shear strength for the coated conjunctional surfaces must be obtained. Due to the aforementioned wear process and formation of transfer film, the surface topography of the load bearing ring face-width as well as its coefficient of boundary shear strength (i.e. asperity summit coefficient of friction) alter, and not often adequately accounted for in ring-bore analyses. This parameter $\varsigma$ is necessary for use in equation (8). Before, proceeding to obtain $\varsigma$, it is essential to calibrate the AFM used. For this purpose a piece of silicon wafer is cleaned for 10 minutes in acetone and in an ultrasound bath. For calibration, the lateral forces, TMR (Trace Minus Retrace) is first obtained, this being a plot of friction (V) against the applied load (nN).

The normal load applied by the AFM is given as [36]:

$\Delta F_{N}=k_{N} \frac{\Delta I_{N}}{S_{N}}$

where, $k_{N}$ is the normal spring constant, $S_{N}$ (normal) sensitivity of the AFM's photodiode and $\Delta I_{N}$ is the signal from the detection scheme corresponding to the deflection of the cantilever in the normal direction.

In addition, the lateral force is calculated as follows:

$\Delta F_{T}=\left(\frac{3}{2} \frac{R}{L}\right) k_{T} \frac{\Delta I_{T}}{S_{T}}$ 
where, $k_{T}$ is the torsional spring constant, $S_{T}$ (torsional) sensitivity of the photodiode and $\Delta I_{T}$ is the signal from the detection scheme of the torsional deflection of the cantilever. $R$ is the length (height) of the cantilever tip and $L$ is length of the cantilever.

It should be noted that [36]: $S_{N}=S_{T}=S$. However, these have been made distinct from one another to make the current analysis generic.

The coefficient of boundary shear strength is defined as:

$\varsigma=\frac{\Delta F_{T}}{\Delta F_{N}}$

Replacing to the corresponding values:

$\varsigma=\left(\frac{3}{2} \frac{R}{L}\right) \frac{S_{N}}{S_{T}} \frac{k_{T}}{k_{N}} \frac{\Delta I_{T}}{\Delta I_{N}}$

Let:

$\psi=\left(\frac{3}{2} \frac{R}{L}\right) \frac{S_{N}}{S_{T}} \frac{k_{T}}{k_{N}}$

Then:

$\varsigma=\psi\left(\frac{\Delta I_{T}}{\Delta I_{N}}\right)$

With the stiffness of the AFM cantilever given as [36]:

$k_{N}=\frac{E W T^{3}}{4 L^{3}}$

and

$k_{T}=\frac{G W T^{3}}{3 L R^{2}}$

Since $G=\frac{E}{2(1+v)}$, then:

$\psi=\left(\frac{1}{1+v}\right)\left(\frac{L}{R}\right) \frac{S_{N}}{S_{T}}$

Now knowing coefficient of friction for silicon samples: $\varsigma_{S i}=0.19 \pm 0.1$ [52] or $\varsigma_{S i}=$ $0.18 \pm 0.03$ [34], the value of $\psi$ for the AFM and the tip used is obtained as follows:

a. Apply a load on the silicon sample. This load in electrical signal form and in units of volts would be $\Delta I_{N}^{c a l}$ (or $\Delta I_{N}^{S i}$ ).

b. Measure the friction force for the silicon sample in electrical signal form (TMR) in units of volts. This is shown by $\Delta I_{T}^{c a l}$ (or $\Delta I_{T}^{S i}$ ). 
c. Draw $\Delta I_{T}^{c a l}$ vs. $\Delta I_{N}^{c a l}$ and apply a linear fit

The slope of the resulted line is called $m_{S i}$ :

$$
m_{S i}=\left(\frac{\Delta I_{T}^{c a l}}{\Delta I_{N}^{c a l}}\right)_{\text {slope }}
$$

d. Calculate: $\psi=\frac{\varsigma_{S i}}{m_{S i}}$

Segments were cut from both the brand new and the worn rings and mounted onto a rectangular holder so that the face-width (contact face) of the ring pieces were exposed for measurement. The AFM was used in its contact mode and the scan size was adjusted for every surface and varied from 5 to $30 \mu^{2}$ with the tip velocity of $20 \mu \mathrm{m} / \mathrm{s}$. With the value of $\psi$ preciously determined and AFM measurements obtained in LFM mode, the value of $\varsigma$ was determined from equation (A-6). These are listed in Table 2. 